(3)

Volume 21, 2018

\title{
COMMUNICATING TRANSDISCIPLINARY CHARACTERISTICS IN GLOBAL REGULATORY AFFAIRS: AN EXAMPLE FROM HEALTH PROFESSIONS EDUCATION
}

Daniela Drago*

Paige L. McDonald

Gaetano R. Lotrecchiano

* Corresponding author
George Washington University, Washington, DC, USA

George Washington University, Washington, DC, USA

George Washington University, Washington, DC, USA drago@gwu.edu

paigem@gwu.edu

glotrecc@gwu.edu

\section{ABSTRACT}

Aim/Purpose

This paper describes the regulatory affairs discipline as a useful case in the study of both inter- and transdisciplinary science and dynamics related to communication across multiple boundaries. We will 1) outline the process that led to the development of transnational competencies for regulatory affairs graduate education, 2) discuss how the process highlights the transdisciplinary character of regulatory affairs, 3) provide implications for how to communicate the influence of this characterization to future healthcare professionals, and 4) draw conclusions regarding how our lessons-learned might inform other programs of study.

Background In the past few decades, the regulatory affairs profession has become more internationalized. This prompted the need for new competencies grounded in the transnational and cross-disciplinary contexts in which these professionals are required to operate.

Methodology A convenience sample of experienced regulatory affairs professionals from multiple disciplines contributed to the development of transnational competencies for a master's program in regulatory affairs using a transdisciplinary framework.

Contribution An applied exemplar in which to understand how transdisciplinary characteristics can be communicated and applied in higher education.

This paper is one in a Special Series on Transdisciplinary Communication

Accepting Editor Shalini Misra | Received: September 28, 2017 | Revised: March 17, April 13, 2018 | Accepted: April 16, 2018.

Cite as: Drago, D., McDonald, P. L., \& Lotrecchiano, G. L. (2018). Communicating transdisciplinary characteristics in global regulatory affairs: An example from health professions education. Informing Science: the International Journal of an Emerging Transdiscipline, 21, 219-234. https://doi.org/10.28945/4030

(CC BY-NC 4.0) This article is licensed to you under a Creative Commons Attribution-NonCommercial 4.0 International License. When you copy and redistribute this paper in full or in part, you need to provide proper attribution to it to ensure that others can later locate this work (and to ensure that others do not accuse you of plagiarism). You may (and we encourage you to) adapt, remix, transform, and build upon the material for any non-commercial purposes. This license does not permit you to use this material for commercial purposes. 
Recommendations This paper recommends how competencies developed from a regulatory affairs for Practitioners program can serve as exemplars for other applied transdisciplinary higher education programs.

Impact on Society This framework provides a seldom-used reflective approach to regulatory affairs education that utilizes cross-disciplinary theory to inform competence-based formation of professionals.

Keywords transdisciplinary, competencies, regulatory affairs, higher education

\section{INTRODUCTION}

Regulatory affairs is a relatively new field and academic discipline in the health professions. It was developed from the desire of governments to protect the public health by controlling the quality, safety, and efficacy of healthcare products (such as pharmaceuticals, biologics, medical devices, and diagnostics). The companies responsible for the discovery, testing, manufacturing, and marketing of these products also need to ensure that they supply suitable products. Regulatory professionals use the principles of science, law, and business to ensure that patients and consumers have quality products that are safe and effective. The responsibilities of regulatory affairs professionals often start in the research and development phases, and extend through premarket approvals, manufacturing, testing, labeling and advertising, and post-market surveillance. The significant investments and advances in basic science research should be transformed into healthcare products that improve the public health, and regulatory affairs professionals play a pivotal role on reaching this objective. Today, more than ever, the development and application of regulatory affairs requires a well-educated, scientifically engaged, and motivated workforce.

In 2010, due to the growing attention to this rapidly changing field, The George Washington University (GWU) launched the Master of Science in Health Sciences in Regulatory Affairs degree program. Originally, the regulatory affairs program at GWU had a purely domestic focus. It was initially designed to cover the regulatory aspects of bringing a new FDA-regulated product to the United States market. However, the advancing globalization of the life-science field (Carroll \& Blair, 2008), the opening of new emerging markets, and other factors increasingly require new professionals to be proficient not only in national but also in international regulations governing regulated products (Drago, Yap, \& Ekmecki, 2016). This situation demands the targeted training of a new generation of professionals, as well as the further qualification of those already working in the regulatory affairs field (Drago, Alsbury, \& Connolly, 2017). Candidates seeking to enroll in a regulatory affairs master's program are aware of these new demands in the workplace and are increasingly interested in a curriculum that includes an international perspective. Also, employers in the private sector are increasingly looking for professionals who develop regulatory strategies aligned with international business objectives. These shifts in the professional landscape have revealed the need for transnational and cross-disciplinary approaches in education and training within regulatory affairs. This seems to be in line with an increasing interest in programs of study that have an internationalized curriculum and support the development of transnational knowledge (Barrie, Hughes, \& Smith, 2009; Maringe \& Foskett, 2010).

\section{PURPOSE}

In response to these shifts in the regulatory landscape, the faculty at GWU initiated a process of developing new competencies for graduates of the regulatory affairs master's program which transcend national requirements as a "strategic response to globalization" (Eaton, Redmon, \& Bax, 2011, p. 562). The process of developing the competencies revealed the cross-disciplinary nature of regulatory affairs and the potential for this field to serve as an exemplar of a scientific field which crosses distinct disciplinary boundaries. It also highlighted the critical role of effective in-group communica- 
tion in developing competencies, which transcend specific disciplinary requirements to achieve global needs. Communication is a "primary, constitutive social process" (Craig, 1999, p. 126) by which shared understanding is achieved. Cross-disciplinary collaboration can achieve transdisciplinary outcomes only through effective communication. In this instance, it was effective in-group communication that enabled the development of an internationalized curricula. In addition, this example highlights effective communication as a requisite competency within any field of science in which future professionals must engage in cross-disciplinary collaboration to meet global challenges.

\section{BACKGROUND}

The requirement for emphasis on cross-disciplinary competencies is not unique to Regulatory Affairs. The quest for embedding graduate education in more transdisciplinary approaches has been a sought-after preoccupation in higher education studies for some time (Bernstein, 2015). Scholarship in this area has a wide range of concerns (Klein 2005; Magrane, Khan, Pigeon, Leadley, \& Grigsby, 2010). For the purpose of this paper and its emphasis on transnational competence in crossdisciplinary training, however, a few aspects of this discourse are of most importance. Such aspects can be grounded in the following definition of transdisciplinarity and its impact on education:

Transdisciplinarity represents the capable germ to promote an endogenous development of the evolutionary spirit of internal critical consciousness.... Respect, solidarity and cooperation should be global standards for the entire human development with no boundaries. This requires a radical change in the ontological models of sustainable development, global education and world-society. We must rely on the recognition of a plurality of models, cultures and socio-economic diversification. As well as biodiversity is the way for the emergence of new species, cultural diversity represents the creative potential of world-society. (Collado, 2013, para. 2)

The necessity for emerging scholars in higher education to be intimately aware of stakeholder connections and how these relationships contribute to problem solving is a critical aspect of professional training in higher education (Rhoten \& Pfirman, 2007). These relationships span beyond academia to include industry, problem-affected partners, cross-national and cross-sector partners and those who are on the front lines of policy building. To effectively encourage such rich partnerships with students requires pedagogic techniques that utilize co-teaching, less structure, increased advising, and more outreach (Pfirman et al., 2011). Such techniques strive to embed into more technologicallybased professions competencies that are grounded in general transdisciplinary perspectives: application of comprehensive problem exploration to include a consideration of the context and frame of reference within wicked problems, negotiation and exposition of boundaries between disciplines, understanding of implicit assumptions, application of processes of inquiry and resulting knowledge as disciplines are crossed and boundaries minimized, respect for life and human dignity and an overall desire to apply knowledge to the betterment of humanity (Mahan, 1970). Of course, these priorities beg the question of why a globalized world needs transdisciplinarity and why emerging scholars and professionals need to be trained to be able to manage wicked problems of the $21^{\text {st }}$ century. As Bill and Klein (2001) have stated, a transdisciplinary world view precipitates a new frame of problem solving that not only includes technical and scientific concerns but also includes the economic, technical, political, social, and regional challenges that are embedded within scientific and professional problems that make them wicked in nature. This integrative process, which for many in higher education challenges their ability to cross-sectors of knowledge, requires non-linear approaches that emphasize the importance of defining the breadth of problems; determining all of the knowledge needed; developing frameworks; specifying the particular studies necessary; engaging in role negotiation (teamwork); building communications; and collating, integrating, confirming knowledge that leads to ultimate decision making about problem-solving (Klein, 1990).

Across health professions fields, educators must prepare future practitioners and scholars with the competencies needed to solve the complex problems of today's healthcare systems. Such skills are 
essential to resolve wicked problems professionals and scholars in translational science face in today's healthcare environment (Brown, Harris, \& Russell, 2010; Lotrecchiano, McDonald, Corcoran, Harwood, \& Ekmekci, 2016). These problems include 1) effectively using basic science discoveries to develop new safe and effective treatments for diseases, 2) improving utilization of new therapies in clinical practice, and 3) streamlining regulatory issues for the development and commercialization of new diagnostics and therapeutics. The three topics listed above can all be regarded as "wicked" problems as they potentially contain one or more conditions contributing to their complexity: a) incomplete or contradictory knowledge, b) a multiplicity of opinions on the subject, c) large-scale burden inclusive of economics, and d) innate interconnections with other problems (Hirsch Hadorn et al., 2007). Their complex nature necessitates interdisciplinary and transdisciplinary approaches (Brown et al., 2010) to knowledge generation. Such cross-disciplinary approaches have become hallmarks in health research, service, education, and policy-making (Choi \& Pak, 2007).

While cross-disciplinary approaches have become critical within health, developing an appreciation for the collaborative dynamics required to achieve cross-disciplinarity among health professionals traditionally reliant upon unique disciplinary approaches to problem-solving proves challenging. The absence of inter-disciplinary and transdisciplinary exemplars inhibits the ability of faculty to create shared understanding among students of the "how" and "why" of these approaches. The process of creating global competencies for the GWU regulatory affairs master's program provides an exemplar of the requirement for an interplay of disciplines to meet the needs of an ever-changing healthcare system. As such, it serves as a mechanism by which faculty can communicate the value of crossdisciplinary approaches and the ways in which collaborative dynamics support the achievement of transdisciplinary outcomes. This paper describes the regulatory affairs inter-discipline as a useful case in the study of both inter- and transdisciplinary science and dynamics related to communication across multiple boundaries. We will:

- Outline the process that led to the development of global competencies,

- Discuss how the process highlights transdisciplinary aspects of regulatory affairs, and

- Consider how to communicate the influence of this characterization to future healthcare professionals within higher education settings

- Draw conclusions regarding how our lessons-learned might inform other programs of study.

\section{TRANSDISCIPLINARY CHARACTERISTICS AND ASSUMPTIONS}

Transdisciplinary workforce environments are intentional collaborative engagements where effective communication yields boundary crossing discourse which precipitates filling gaps between disciplines (Craig, 2007), generating new knowledge, and fostering collaboration as a normative operative aspect of professional effectiveness. Intergroup communication is a key consideration for how transdisciplinary networks operate to achieve these goals (Stewart et al., 2010). This stated, transdisciplinarity is:

an unlikely constant state in social systems. It may at times be a novel outcome of team collaborations and at other times may be dormant to more apparent and less innovation generating multi- and interdisciplinary interactions embedded within group interactions. (Klein, 2008)

Research trends continued to favor the measurement of transdisciplinary engagement through variable-centered means isolating the importance of identification of occurrences of identifiable transdisciplinary behaviors over the meaning and explanation of the mechanistic tendencies associated with such occurrences (Hedström \& Swedberg, 1998). This type of 'individualistic behavioralism' (Coleman, 1986) and its emphasis on social determinants can distract from inquiry that isolates and describes social influences and does not focus on the causal relationships between social factors. This 
differentiation is critical in the study of transdisciplinary teams and their exercise of effectiveness. "As the prefix 'trans' indicates, transdisciplinarity concerns that which is at once between disciplines, across the different disciplines, and beyond all disciplines" (Nicolescu, 2002, pp. 44-45). According to Maasen and Lieven (2006), transdisciplinarity is a new mode of governing science sufficiently. This new mode has become increasingly important in a global climate of societies that test proofs of science, where civic responsibility goes hand-in-hand with scientific endeavors and science has become increasingly an enterprise engagement. More than ever "knowledge production ultimately relies on its participants addressing each other as members of a common citizenry...in this capacity and the social responsibility deriving from it, they have to synthesize their respective knowledge and stakes according to the Common Good" (Maasen \& Lieven, 2006, p. 48).

Klein (2008), Nicolescu (2002), and Maasen and Lieven (2006) all describe a global scientific social arrangement where complexity is a common factor in understanding how knowledge and thought are generated and interact in transdisciplinary settings. These settings are both emergent and complex and unpredictable and depend on interactions to generate new realities within their systems. These complex adaptive systems (CAS), or systems comprised of "semi-autonomous agents that recombine into new capabilities as a mechanism of adaptation" (Hazy, Goldstein, \& Lichtenstein, 2007, p. 5), are emergent environments where plasticity, irritability, variety, selectivity, preservation, and propagation are key elements in the process of shifting to a paradigm where semi-permanence is a steady state. These theories serve as a helpful construct in understanding transdisciplinarity as an emergent and interactive mechanism within global teams and networks where change is a constant and adaptability is a requirement (Buckley, 1998).

Evaluation strategies that consider not only the dynamics of transdisciplinary phenomena but also the evaluation of transdisciplinary interactions are emerging with particular evidence-based principles for furthering the field (Holmes et al., 2008; Klein, 2008; Kozlowski \& Ilgen, 2007). These strategies are of interest in sectors where coordination, innovation, and transdisciplinary interactions are expected outcomes and successful coordination is measured through interfacing agents rather than individual manager-centered leadership. Three main assumptive components of transdisciplinary communications, therefore, are critical to the discussion of globalization and skills and competencies of professionals entering team and network arrangements.

First, complex networks of stakeholders in a transdisciplinary environment make up communities of influential individual, group, organizational, and environmental agents often representing global cross-national partners. As such, as in the growth of a global enterprise like health and biomedical regulation, a number of competency-based skills are needed to navigate the national, linguistic, cultural and governing characteristics found within a global dialogue. A transdisciplinary environment of this sort is one where a variety of unrelated influences defined by global differences become catalysts of knowledge exchange and therefore represent a complex array of agents. From a pragmatic perspective, communication can yield metadiscursive vocabulary critical to achieving shared meaning representative of interdependence, pluralism and cooperation (Craig, 2007). The resulting common understanding can then serve as the basis for the generation of new knowledge, which both transcends and represents individual/disciplinary interests. Effectiveness of the professionals that participate in this boundary crossing activity will regularly transcend the confinements of individual or single community interests and expand the concept of cooperation beyond mere interactions between entities to a collective enterprise of new knowledge generation as a result. An understanding of how this achievement of transcendence occurs is beneficial for teams whose operational mandates include generating novel and innovative perspectives and processes.

Second, dynamism in transdisciplinary environments is evidenced by social mechanisms that serve as measurable indicators of successful interactions and the crossing of social and thought boundaries (Hedström \& Swedberg, 1998). These mechanisms serve as an explanation of social phenomena, taking into account not just why something happens but the causal mechanisms that indicate why and how it occurs (Elster, 1989). The development of these types of social mechanisms is of par- 
ticular significance when evaluating the interactions of teams and networks, where novel, blended, and innovative outcomes are measures of successful collaboration between like and different-minded stakeholders. Differing social and thought traditions can ascribe different meanings to phenomena under consideration, which inhibits the development of shared meanings essential to effective communication. The shift from independent and self-organized disciplinary views often bound by national protocols to collective viewpoints requiring blended and often compromised outcomes yield new paradigms of engagement. New definitions of influence and normality may be recognized within and across specific communities of knowledge.

Third, interdependence of thought and action is critical to a transdisciplinary environment. Interdependence in teams actuates when individuals work together but their own individual and professional roles are expanded (and challenged) to include the integrated and emergent knowledge which is otherwise unattainable unless in a dynamic transdisciplinary relationship with others. It is a knowledge paradox that typifies the transdisciplinary paradigm. "The model presupposes the distinction between an 'outer world' on the one hand and human knowledge production that slowly accumulates a growing stock of knowledge on the other" (Weingart, 2000, p. 37). Individuals within this paradox become considered along with other equally dynamics entities within a system. In other words, individual change is expected along with the changing structures, protocols, and cultures that are a result of the interdependence that comes with transdisciplinary engagement. Social interaction, therefore, is intrinsically linked to the accumulation of knowledge as teams engage for it is through interchanges where individual awareness is tested against growing, evolving, and new social standards (Polanyi, 1958). A transdisciplinary environment is one where reciprocal interdependence between team stakeholders and, more importantly, the other social agents is a standard consideration in striving for integrative knowledge and services (Thompson, 1967).

\section{Method: The Process of Developing Transnational COMPETENCIES}

The director of the regulatory affairs program began with a comprehensive evaluation of the existing curriculum. The domestic focus of all regulatory courses became immediately apparent. The curriculum did not reflect the globalization of this life-science field, which forces regulatory professionals to be familiar with international regulations. To ensure that the program incorporates skills that meet today's needs, the director of the regulatory affairs program led efforts to redesign and implement changes to the curriculum. Specifically, the team:

- Conducted a literature search for existing competencies;

- Identified the academic and career needs for the profession, and drafted the key competencies graduates are expected to master upon graduation;

- Conducted semi-structured interviews with selected adjunct faculty and a newly formed external advisory board to inform curricular redesign;

- Grouped the drafted competencies into program outcomes;

- Changed the focus from a domestic oriented curriculum to one that integrates an international perspective;

- Identified courses in which program outcomes would be introduced, developed, and mastered;

- Mapped the program outcomes to course learning objectives;

- Modified the curriculum and developed a new program of study;

- Developed an annual evaluation system for continual improvement.

Further details of the process that the interdisciplinary team used to generate the new competencies are provided below. 


\section{LITERATURE SEARCH AND CREATION OF INTERDISCIPLINARY TEAM}

The director of the regulatory affairs program began with a literature search of both scholarly and trade publications. The aim was to identify a published set of competencies that an interdisciplinary team of faculty in the program could modify and adapt. Little was found with a direct reference to competencies for a curriculum in global regulatory affairs. In 2010, the Association of Graduate Regulatory Educators (AGRE) initiated - in collaboration with multiple stakeholders - the development of core competencies for graduates of Master of Science programs in regulatory studies (Shire, Swanson, Drago, \& Feagin, 2014). According to AGRE, the five critical areas for the competencybased curricula consist of (1) regulations, (2) clinical trials, (3) quality, (4) communication, and (5) strategy.

To discuss the findings of the literature search and develop the first set of new transnational competencies for the GWU program, the director of the regulatory affairs program created an interdisciplinary team. The team consisted of GWU faculty members, members of the School of Medicine and Health Science's Curriculum Committee (SMHS-CC), and regulatory officials that had experience working in the regulated-industry or at the FDA. Communication across these disciplines was essential to completing a review process which identified limitations in existing curricula. The team reviewed the AGRE competencies and also referred to the original competencies that GWU had developed for the regulatory affairs curriculum. As mentioned earlier, these original competencies had only a domestic focus. To develop the first set of new competencies, the multifunctional team reviewed additional resources. Specifically, the competencies and learning objectives published by two professional organizations: the Regulatory Affairs Professionals Society (RAPS), a US-based professional organization (http://www.raps.org/about/), and The Organization for Professionals in Regulatory Affairs (TOPRA), a UK-based professional organization (https://www.topra.org/abouttopra). TOPRA, in collaboration with the University of Hertfordshire, offers a Master of Science (MS) in Regulatory Affairs with a focus on pharmaceuticals (TOPRA, 2013). Additionally, TOPRA, in collaboration with Cranfield University, offers also a MS in Regulatory Affairs with a focus on medical devices development. Based on an analysis of all the information collected, the members of the interdisciplinary team drafted the key competencies that graduates of the GWU regulatory affairs program are expected to master upon graduation.

\section{INTER VIEWS WITH SUBJECT MATTER EXPERTS AND MEETINGS WITH EXTERNAL ADVISORY BOARD}

Subsequently, the director of the regulatory affairs program conducted semi-structured interviews with subject matter experts (SMEs). The director of the regulatory affairs program convened a convenience sample of credible professionals with at least 15 years of experience in the field who were willing to devote time to this project. Some of the SMEs were members of the faculty that teach in the regulatory program but were not involved in the first step of the process. Others were regulatory experts working for the regulated industry, health authorities, and trade associations. The intent of was to achieve consensus on the competencies. Despite disparity of experience and background, the group collaborated with enthusiasm and reached consensus.

\section{COMPETENCY MAPPING AND GAP ANALYSIS}

Curriculum mapping is a recognized method that helps to identify and illustrate where within the curriculum, program goals are addressed and learning outcomes are achieved. It can also serve as a tool to facilitate common understanding among multiple stakeholders developing a curriculum. The process that governed the subsequent part of the project, the competency mapping and gap analysis, can be summarized as follows:

a) the set of key competencies that were identified were grouped into major program outcomes; 
b) the program outcomes were then mapped to course learning objectives; and

c) courses in which program outcomes (as a set of competencies) were Introduced, Developed, and Mastered were identified and denoted as such.

The competency mapping and gap analysis process resulted in new program student outcomes that address the following six domains: regulations, quality and compliance, clinical and pre-clinical, communication and leadership, strategy, and business acumen. The competency mapping process facilitated shared understanding across disciplines of requisites needed to achieve the transnational competencies. Examples of the newly developed transnational competencies are reported in Table 1. Further discussion of the relationship between these competencies and their transdisciplinary characteristics described earlier in this special issue (Lotrecchiano \& Misra, 2018) will be discussed in the section below.

Table 1 - Transdisciplinary Characteristics Associated with Examples of Transnational Competency.

\begin{tabular}{|c|c|}
\hline Characteristics & Examples of Transnational Competencies \\
\hline $\begin{array}{l}\text { Multidimensional, human and natu- } \\
\text { ral system interfaces. }\end{array}$ & $\begin{array}{l}\text { - Evaluate the global healthcare environment and its potential impact on } \\
\text { the organization. } \\
\text { - Identify and interpret laws, regulations, and guidance documents for do- } \\
\text { mestic and international agencies relevant to the development and commer- } \\
\text { cialization of healthcare products }\end{array}$ \\
\hline $\begin{array}{l}\text { Information exchanges across } \\
\text { boundaries }\end{array}$ & $\begin{array}{l}\text { - Evaluate best practices that support the continuous improvement of the } \\
\text { quality system. } \\
\text { - Develop a proposal for initiating a key strategic change initiative within } \\
\text { the field of regulatory affairs. }\end{array}$ \\
\hline Theory and application interaction & $\begin{array}{l}\text { - Advise on the conduct of ethical pre-clinical and clinical studies according } \\
\text { to international standards. } \\
\text { - Identify quality requirements for the development and post-market } \\
\text { maintenance of healthcare products }\end{array}$ \\
\hline $\begin{array}{l}\text { Collaborative deconstruction } \\
\text { Deconstructing and reconstructing } \\
\text { relationships }\end{array}$ & $\begin{array}{l}\text { - Develop regulatory strategies to bring new healthcare products to market } \\
\text { that support business objectives and are in compliance with regulatory re- } \\
\text { quirement. } \\
\text { - Analyze communication from domestic and international health authori- } \\
\text { ties and respond appropriately. }\end{array}$ \\
\hline $\begin{array}{l}\text { Stakeholder involvement } \\
\text { Involvement as a means of invest- } \\
\text { ing in outcomes }\end{array}$ & $\begin{array}{l}\text { - Identify the critical elements for successful outcomes in organizational and } \\
\text { process change. }\end{array}$ \\
\hline
\end{tabular}


Drago, McDonald, \& Lotrecchiano

\section{DISCUSSION: TRANSDISCIPLINARY ASPECTS OF REGULATORY AFFAIRS}

National regulatory authorities around the world share similar objectives. Most review and approval processes of pharmaceutical products are based on the criteria of quality, safety, and efficacy. However, regulators act independently in implementing processes and systems to achieve these objectives and, as a result, national laws, regulations, guidelines, and requirements vary. Different regulators can reach different decisions even when reviewing similar data. Clear predictors of regulatory outcomes are difficult to identify and are still unknown.

The reasons for different decisions are likely to be multifactorial. Both intrinsic and extrinsic factors can play a role. Examples of intrinsic factors are "genetic polymorphism, age, gender, height, weight, lean body mass, body composition, and organ dysfunction" (Edwards et al., 2011). Such factors influence, for example, the applicability/acceptability of foreign clinical data for a given application. Extrinsic factors, on the other end, include "the social and cultural aspects of a region such as medical practice, diet, use of tobacco, use of alcohol, exposure to pollution and sunshine, socio-economic status, compliance with prescribed medications, and, particularly important to the reliance on studies from a different region, practices in clinical trial design and conduct." (International Council for Harmonisation, 1998, p.8) In the literature, many reasons have been suggested for the differences in regulatory approach and policy in different regions. Often, social and philosophical differences, which might have arisen from different historical experiences, along with differences in culture, have been emphasized. These differences can inhibit the development of shared understanding requisite for complex problem solving. For instance, patients in the EU seem to be more risk averse based on the negative experiences with thalidomide from the 1960s. Risk-aversion seems to be even more pronounced in Japan where thalidomide was also on the market for 5 years (1958-1963) and was sold without a prescription. In the US, the vigilance of FDA medical officer Dr. Frances Kelsey prevented a public health tragedy (Bren, 2001).

It is well recognized that there are worldwide differences in approved dosing in different regions of the world (Huang \& Temple, 2008; Malinowsk, Westelinck, Sato, \& Ong, 2008). In particular, such differences have been reported for drugs approved in the United States, Europe, and Japan. Dosing in Japan is often considerably lower than in the United States or Europe, but some differences in dosing are also apparent between the United States and Europe as well.

The regulatory guideline titled "Dose-Response Information to Support Drug Registration" confirms the possibility that "different physicians and even different regulatory authorities would, looking at the same data, make different choices as to the appropriate starting doses, dose titration steps, and maximum recommended dose, based on different perceptions of risk/benefit relationships" (International Council for Harmonisation, 1994, p.1). While the underlying causes for dosing differences between the US, the EU, and Japan have not been established, it has been theorized that differences in dosing may be attributable to intrinsic ethnic factors (e.g., genetics, metabolism, and elimination), extrinsic ethnic factors that are associated with environment and culture (e.g., medical practice, diet, use of alcohol, and concomitant drug use), or interactions among these factors.

Globalization, competition, and a rapidly changing business environment have started forcing regulatory professionals working in companies, governmental agencies, and other organizations to focus more on Complex Problem Solving. Those professionals, who are operating in a highly-regulated environment, must face additional challenges than others who can still focus and operate in a purely domestic environment. Today's manufacturing processes and supply chains of medicinal products are increasingly complex. Products are often distributed all over the world and used by patients in several different countries.

It is important to highlight that there is no single global, systematic, and consistent approach to the approval of prescription drugs. While agencies' specific requirements for submission of data are dif- 
ferent, the dossier submitted to different agencies may be similar. However, even in the case where dossiers contain similar data, different agencies may draw different conclusions from their review of the data, which may lead to differences in product labeling and even different regulatory actions. As has been noted:

All agencies have the same objectives and obligations to safeguard public health when assessing the safety, quality, and efficacy of medicines before they are authorized for marketing. However, the structure, strategies, practices, processes, and regulatory and legal obligations in place at each agency in order to carry out a regulatory review and achieve these objectives vary considerably. (Hirako, McAuslane, Salek, Anderson, \& Walker, 2007, p. 291)

Over the last couple of decades, in an attempt to reduce healthcare costs globally as well as accelerate drug development, national regulatory agencies initiated efforts to work collaboratively. Most notably, in 1990, representatives from the regulatory authorities in the US, Europe, and Japan, in collaboration with the respective industry associations, started a major international project: The International Conference on Harmonization of Technical Requirements for Registration of Pharmaceuticals for Human Use (ICH) (Vozeh, 1995). The key objectives of ICH had been defined as:

- To establish constructive scientific dialogue on the differences in registration requirements

- To identify areas of mutual acceptance of research results without compromising safety

- To recommend practical ways to achieve greater harmonization of registration requirements

- To reduce the unethical repetition of tests in animals and humans (van der Laan \& DeGeorge, 2013).

The purpose of the ICH initiative (now renamed International Council on Harmonization) was to reduce the high cost and length of time involved in duplicating pharmaceutical research and development within the three regions. For instance, an important initiative was the harmonization of the dossier's format (known as the Common Technical Document or CTD). Up until the adoption of the CTD, the format and content of a New Drug Application (NDA) in the US, a Marketing Authorization Application (MAA) in Europe, and a Japanese NDA (J-NDA) differed significantly.

Before and through the late 1990s, companies that sought to enter the Japanese market were required to conduct a full independent clinical development program with Japanese patients (in Japan). At that time, Japanese clinical development programs, typically involved smaller patient populations than Western programs. With the introduction of the ICH guideline ICH E5, "Guideline on Ethnic Factors in the Acceptability of Foreign Clinical Data," the Japanese regulatory authority started to accept limited non-Japanese clinical data to support an application for a marketing authorization (International Council for Harmonisation, 1998). The aim of the ICH E5 guideline is to recommend strategies that allow the use of clinical data collected in one region to be used for the support of a drug application in another region by introducing the concept of "bridging studies." Bridging studies are generated to extrapolate or 'bridge' the clinical data between the two regions (e.g. the US and Japan). The applicability of a bridging strategy depends on the degree of similarity of intrinsic and extrinsic factors between the two regions. This is an example of how the regulatory field fulfills the characteristic of Praxis (Lotrecchiano \& Misra, 2018).

The healthcare landscape, and the regulatory profession, has evolved greatly ever since the inception of ICH. This was mainly in response to new technologies, increasing regulations, and improved understanding and expectations of patients' needs. Also, from a technology perspective, recent years have seen a remarkable drive towards advancements in genomic mapping, personalized medicine, and novel monoclonal antibodies therapies for oncology, which initiated many changes that had an impact on today's regulatory professionals. 
Some regulators in some countries may lack the specific competences or resources to evaluate some of these new complex products. To avoid duplication of work, ensure a good and efficient allocation of resources and accelerate patient's access to new products, regulators are increasingly embracing a (more) Open System. Awareness of the need for regulators to work together across boundaries has led to the emergence of new models of cooperation. "In an increasingly globalized pharmaceutical market, collaboration between medicines' regulators is essential," explains the EMA's Executive Director Guido Rasi. "Medicines' regulators are inter-dependent: any action taken in one territory has repercussions on the rest of the world. International cooperation is a key area of work for the Agency" Masangsky, 2014, para. 5 ). According to Janet Woodcock, M.D., Director of the FDA's Center for Drug Evaluation and Research, protecting the health and safety of the American people requires collaboration: "It is part of a larger collaborative global effort between the FDA and its international regulatory partners to ensure the health and safety of all our citizens" (Masangkay, para. 4).

Regulators, industry, and other stakeholders see the benefit of strengthening the regulatory systems through convergence, reliance, and recognition. Several initiatives are underway and there is an increasing participation from regulators in multilateral/global initiatives. A good example of a long existing regulatory cooperation between medicine's authorities is the European system. Its legal basis dated back to 1965. Other countries and regions have also developed or are developing frameworks for cooperation through convergence, reliance, and recognition. Such systems help avoid duplication and use resources efficiently.

Most companies, nowadays, operate development projects using multifunctional project teams. Often, regulatory affairs professionals are not only dealing with many different functions spread around the company but also in different parts of the world. In a large company, scientists have a deep knowledge of the specific project but also access to technical specialists with expertise that cuts across multiple regulatory applications. This expertise should be built into multifunctional project. Therefore, many companies moved towards 'matrix' project teams to ensure that the review of regulatory applications includes a cross-cutting component in addition to the functional line or professional line view. This approach leads to opportunities for regulatory affairs issues and opportunities to be approached with collaborative deconstruction and methodological pluralism.

Stakeholder involvement is at the core of regulatory affairs as a discipline. Representation from key disciplines - clinical research, toxicology, pharmacology, manufacturing, technical operation, quality assurance, legal, marketing, etc. - is essential for the success of drug development. A cross-functional model allows companies to bridge the gap between $\mathrm{R} \& \mathrm{D}$, regulatory approval, and commercialization. Today's regulatory professionals are expected to provide strategic influence on the clinical development process. They are also deeply involved in delivering commercial and medical input for various teams throughout the organization. Regularly, internal cross-functional communication, especially with clinical and $\mathrm{R} \& \mathrm{D}$ teams, empowers regulatory affairs to more significantly impact product development. Allowing regulatory affairs input when discussing product pipelines also generates more effective trial designs that meet regulatory agencies demands — inevitably saving companies time and money. Engaging with stakeholders is essential to build trust and understanding of the challenges and, without this constant interaction, regulatory professionals could not function. Regulatory professionals interact with stakeholders through a variety of communication channels. They participate in informal and formal/structured engagement, such as meetings, forums and other events, and carry out consultations. For example, today's healthcare landscape is becoming increasingly more patient centric. Multiple stakeholders are not satisfied anymore with companies demonstrating that their product is of good quality and is safe and effective. They now expect companies to address patient needs and demonstrate how their product will enhance patient outcomes. To meet this demand, it is important to find new ways to incorporate the patient perspective into drug research, development, and approval. Regulatory professionals play a pivotal role in this. According to a recent study by Cutting Edge Information, "apart from marketing, the most popular functions that are involved in at least 65\% of surveyed patient-centric initiatives are regulatory and medical affairs" (Marketwire, 2017 
p.1). In Table 1, for each characteristics of a transdisciplinary discipline, we provide some examples of our program's global competencies.

\section{RECOMMENDATIONS FOR COMMUNICATING THE TRANSDISCIPLINARY CHARACTERISTICS WITHIN HIGHER EDUCATION SETTINGS}

Over the past ten years, interdisciplinarity and cross-disciplinary have gained increasing popularity in higher education due to the demands on an increasingly complex and global world (Miller, 2010; Tarrant \& Thiele, 2017). In fact, the ability of universities to educate toward addressing global social challenges of today's era may depend upon the development of future scholars for interdisciplinary and transdisciplinary scholarship (Tarrant \& Thiele, 2017). Though more popular, cross-disciplinary approaches to research and teaching require an appreciation for the collaborative dynamics required to achieve cross-disciplinarity which can be difficult to develop among professionals heavily reliant upon unique disciplinary approaches to problem-solving, such as health professionals. This challenge is further frustrated by the absence of concrete examples of interdisciplines and transdisciplines which can serve as communication mechanisms among faculty and students to facilitate shared understanding the "how" and "why" these approaches are appropriate to future research and problemsolving.

GWU's regulatory affairs master's program can serve as an exemplar of the type of cross-disciplinary communication required to develop transnational competencies representing the integration of multiple disciplinary perspectives. The process by which global competencies were achieved within this program represents the type of metacognitive discourse necessary to achieve outcomes representing pluralism, interdependence and interdisciplinary agreement (Craig, 2007). Consequently, it could be used by faculty across higher education to develop student appreciation the collaborative dynamics requisite in developing transdisciplinary outcomes.

The alignment between the global competencies developed for regulatory affairs and the characteristics of a transdiscipline will also benefit faculty in higher education tasked with teaching inter, cross and transdisciplinary scholarship. The global competencies can serve as concrete representations of transdisciplinary characteristics that may seem ambiguous to students. As such, they can serve as a mechanism for scaffolding learning experiences from understanding toward application and the creation of new knowledge (Krathwohl, 2002). For future scholars to create new knowledge through cross-disciplinary collaboration, they must first understand the characteristics they are working toward in future interactions.

With regards to health professions education in particular, future health professionals must develop cross-disciplinary competencies in order to solve the wicked problems they will face in practice (Brown et al., 2010; Lotrecchiano et al., 2016). Faculty challenged with imparting these skills require real-world exemplars of inter- and transdisciplinary characteristics within a program of study accessible to students across multiple healthcare disciplines. Adopting the "case" of regulatory affairs across health professions education will help to communicate the benefit of establishing global competencies in emerging fields, which cross disciplinary boundaries. Moreover, it provides a model of the way in which a field of study can adapt to the needs of multiple stakeholders to remain relevant within an increasingly complex healthcare environment.

\section{CONCLUSIONS}

This paper examined the process by which a health sciences inter-discipline developed transnational competencies. These competencies align with the increasingly complex regulatory environment and healthcare landscape. Transdisciplinary characteristics noted in the paper include complex problemsolving, open system, praxis, collaborative deconstruction and stakeholder involvement. 
The process of developing the competencies illuminates cross-disciplinary communication in transdisciplinary programs by illustrating the need for emerging regulatory affairs professionals to have facility in communicating across national and cultural boundaries. Therefore, it can serve as an exemplar case for other higher education programs, specifically for health professions programs, that seek to cross and expand beyond boundaries of any one health context. It illustrates how crossdisciplinary communication is necessary to address complex global problems such as the ones often faced by regulatory affairs professionals. Moreover, the resulting competencies can also provide concrete examples of the transdisciplinary nature of facilitating student understanding in cross national contexts of one particular health field. Those charged with developing learning outlets for healthcare professionals - such as regulatory affairs professionals - have a responsibility to address technical and scientific concerns. In addition, they should also consider the economic, political, social, and other challenges that go hand-in-hand with the problems that the profession must address. In health professions training, this is paramount. The new generations of professionals need to be versed in how to translate knowledge to address increasingly complex health problems.

The process employed by the program director of regulatory affairs at GWU to develop transnational competencies can also serve as a model for other programs seeking to internationalize a curriculum:

- Conducting a literature review for requisite competencies allows the development team to gather a broad picture of the requisite knowledge and skills;

- Consulting with SMEs from industry and academia permits verification and augmentation of the requisite knowledge and skills;

- Mapping the curriculum allows for identification of gaps in existing programming to realign course and content to transnational competencies.

\section{REFERENCES}

Barrie, S., \& Hughes, C. \& Smith, C. D. (2009). The national graduate attributes project: Integration and assessment of graduate attributes in curriculum. Strawberry Hills, New South Wales: Australian Learning and Teaching Council.

Bernstein, J. H. (2015). Transdisciplinarity: A review of its origins, development, and current issues. Journal of Research Practice, 11(1), Article R1. Retrieved from http://jrp.icaap.org/index.php/jrp/article/view/510/412

Bill, A., \& Klein J. T. (2001). Why a globalized world needs transdisciplinarity. In J. T. Klein, R. Häberli, R. W. Scholz, W. Grossenbacher-Mansuy, A. Bill, \& M. Welti M. (Eds), Transdisciplinarity: Joint Problem Solving among Science, Technology, and Society (pp. 24-34). Birkhäuser Verlag: Basel. https://doi.org/10.1007/978-3-0348-8419-8 3

Bren, L. (2001). Frances Oldham Kelsey: FDA medical reviewer leaves her mark on history. FDA Consumer Magazine, 35(2), 24-29.

Brown, V. A., Harris, J. A., \& Russell, J. (2010). Tackling wicked problems: Through the transdisciplinary imagination. New York, NY: Earthscan.

Buckley, W. (1998). Society - A complex adaptive system: Essays in social theory. Amsterdam: Gordon and Beach Publishers.

Carroll, M., \& Blair, J. (2008). Local economic development: Analysis, practices, and globalization. San Francisco: Sage.

Choi, B. C. K., \& Pak, A. W. P. (2007). Multidisciplinarity, interdisciplinarity, and transdisciplinarity in health research, services, education and policy: 2. Promotors, barriers, and strategies of enhancement. Clinical \& Investigative Medicine, 30(6), E224-E232. https://doi.org/10.25011/cim.v30i6.2950

Coleman, J. (1986). Social theory, social research, and a theory of action. American Journal of Sociology, 91(6), 1309-1335. https://doi.org/10.1086/228423 
Communicating Transdisciplinary Characteristics in Global Regulatory Affairs

Collado, J. (2013).Transdisciplinary education as ethic of the diversity reform in the World-Society of the 21st Century. Global Education Magazine. Retrieved from

http://www.globaleducationmagazine.com/transdisciplinary-education-ethic-diversity-reform-worldsociety-21st-century

Craig, R. T. (1999). Communication theory as a field. Communication Theory, 9(2), 119-161. https://doi.org/10.1111/j.1468-2885.1999.tb00355.x

Craig, R. T. (2007). Pragmatism in the field of communication theory. Communication Theory, 17(2), 125-145. https://doi.org/10.1111/j.1468-2885.2007.00292.x

Drago, D., Alsbury S., \& Connolly C. (2017). Promoting excellence in the regulatory affairs profession: A competency framework. Regulatory Rapporteur, 14, 16-19.

Drago, D., Yap, M., \& Ekmecki, O. (2016). Increasing the odds of effective drug development: Elevating regulatory affairs professionals to strategic partners. Clinical Research and Regulatory Affairs, 33, 2-4. https://doi.org/10.3109/10601333.2016.1152661

Eaton, D. M., Redmond, A., \& Bax, N. (2011). Training healthcare professionals for the future: Internationalism and effective inclusion of global health training. Medical Teacher, 33(7), 562-569. https://doi.org/10.3109/0142159X.2011.578470

Edwards, L. D., Husson, J., Labbe, E., Naito, C., Papaluca Amati, M., Walker, S., . . Yasurhara, H. (2011). Racial and ethnic issues in drug regulation. In L. D. Edwards, A. W. Fox, \& P. Stonier (Eds.), Principles and Practice of Pharmacentical Medicine. Chichester, West Sussex: Wiley-Blackwell.

Elster, J. (1989). Nuts and bolts for the social sciences. Cambridge: Cambridge University Press. https://doi.org/10.1017/CBO9780511812255

Hazy, J. K., Goldstein, J. A., \& Lichtenstein, B. B. (2007). Complex systems leadership theory: An introduction. In J. K. Hazy, J. A. Goldstein, \& B. B. Lichtenstein (Eds.), Complex systems leadership theory: New perspectives from complexity science on social and organizational effectiveness (pp.1-16). Mansfield, MA: ISCE Publishing.

Hedström, P., \& Swedberg, R. (1998). Social mechanisms: An analytic approach to social theory. Cambridge: Cambridge University Press. https://doi.org/10.1017/CBO9780511663901

Hirako, M., McAuslane, N., Salek, S., Anderson, C., \& Walker, S. (2007). A comparison of the drug review process at five international regulatory agencies. Drug Information Journal, 41(3), 291-308. https://doi.org/10.1177/009286150704100302

Hirsch Hadorn, G., Hoffmann-Riem, H., Biber-Klemm, S., Grossenbacher-Mansuy, W., Joye, D., Pohl, C., Wiesmann, U., \& Zemp, E. (2007). Handbook of Transdisciplinary Research. Dordrecht, Netherlands: Springer.

Holmes, J. H., Lehman, A., Hade, E., Ferketich, A. K., Sarah, G., Rauscher, G. H., . . Bird, C. E. (2008). Challenges for multilevel health disparities research in a transdisciplinary environment. American Journal of Preventive Medicine, 35(2 Suppl), S182-S192. https://doi.org/10.1016/j.amepre.2008.05.019

Huang, S. M., \& Temple, R. (2008). "Is this the drug or dose for you?" Impact and consideration of ethnic factors in global drug development, regulatory review, and clinical practice. Clinical Pharmacology and Therapeutics, 84(3), 287-295. https://doi.org/10.1038/clpt.2008.144

International Council for Harmonisation. (1994). Dose-response information to support drug registration E4. DoseResponse, E4.

International Council for Harmonisation. (1998, February). Ethnic factors in the acceptability of foreign clinical data E5 (R1). In International Conference on Harmonisation of Technical Requirements for Registration of Pharmaceuticals for Human Use.

Klein, J. T. (1990). Interdisciplinarity: History, theory, and practice. Detroit: Wayne State University Press.

Klein, J. T. (2005). Humanities, culture, and interdisciplinarity: The changing American academy. Albany: SUNY Press.

Klein, J. T. (2008). Evaluation of interdisciplinary and transdisciplinary research. American Journal of Preventative Medicine, 35(2S), S116-S123. https://doi.org/10.1016/j.amepre.2008.05.010 
Kozlowski, S. W. J., \& Ilgen, D. R. (2007). The science of team science. Scientific American Mind, 18(3), 54-61. https://doi.org/10.1038/scientificamericanmind0607-54

Krathwohl, D. R. (2002). A revision of Bloom's taxonomy: An overview. Theory into Practice, 41(4), 212-218. https://doi.org/10.1207/s15430421tip4104 2

Lotrecchiano, G. R., McDonald, P. L., Corcoran, M., Harwood, K., \& Ekmekci, O. (2016). Learning theory, operative model and challenges in developing a framework for collaborative, translational and implementable doctoral research. Paper presented at the International Conference on Educational Research and Innovation, Seville, Spain. https://doi.org/10.21125/iceri.2016.0116

Lotrecchiano, G. R., \& Misra, S. (2018). Transdisciplinary knowledge producing teams: Towards a complex systems perspective. Informing Science: The International Journal of an Emerging Transdiscipline, 21, 51-74. https://doi.org/10.28945/4086

Maasen, S., \& Lieven, O. (2006). Transdisciplinarity: A new mode of governing science? Science \& Public Policy, 33(6), 399-410. https://doi.org/10.3152/147154306781778803

Magrane, D., Khan, O., Pigeon, Y.., Leadley, J., \& Grigsby, R. K. (2010). Learning about teams by participating in teams. Academic Medicine, 85(8), 1303-1311. https://doi.org/10.1097/ACM.0b013e3181e5c07a

Mahan, J. L., Jr. (1970). Toward transdisciplinary inquiry in the humane sciences. Doctoral dissertation, United States International University. UMI No. 702145. Retrieved from ProQuest Dissertations \& Theses Global.

Malinowski, H. J., Westelinck, A., Sato, J., \& Ong, T. (2008). Same drug, different dosing: Differences in dosing for drugs approved in the United States, Europe, and Japan. Journal of Clinical Pharmacology, 48(8), 900-908. https://doi.org/10.1177/0091270008319794

Maringe, F., \& Foskett N. (Eds). (2010). Globalization and internationalization in higher education. Theoretical, strategic and management perspectives. London: Continuum International Publishing Group

Marketwire. (2017). The top 3 pharma functions involved in patient-centric initiatives. Retrieved from http://www.marketwired.com/press-release/top-3-pharma-functions-involved-patient-centric-initiativesapart-from-marketing-2228290.htm

Masangkay, E. G. (2014). FDA and EMA step up collaboration in pharmoacovigilance. Retrieved from https://www.outsourcedpharma.com/doc/fda-and-ema-step-up-collaboration-in-pharmacovigilance-0001

Miller, C. A. (2010). Policy challenges and university reform. In R. Frodeman, J. T. Klein, \& C. Mitcham (Eds.), The Oxford Handbook of Interdisciplinarity (Vol. 333-334). Oxford: Oxford University Press.

Nicolescu, B. (2002). Manifesto of Transdisciplinarity (K.-C. Voss, Trans.). Albany, New York: State University of New York Press.

Polanyi, M. (1958). Personal knowledge: Towards a post-critical philosophy. Chicago: University of Chicago Press.

Pfirman, S., Martin, P., Barry, L., Fletcher, M., Hempel, M., Southard, R., Hornbach, D., \& Morehouse, B. (2011). Interdisciplinary biring, tenure and promotion: Guidance for individuals and institutions. Council of Environmental Deans \& Directors. http://www.uvm.edu/ tri/pdf/NCSE-InterdisciplinaryHiring.pdf

Rhoten, D., \& Pfirman, S. (2007). Women in interdisciplinary science: Exploring preferences and consequences. Research Policy, 36(1).56-75. https://doi.org/10.1016/i.respol.2006.08.001

Shire, S., Swanson, C., Drago, D., \& Feagin, J. (2014). Core competencies provide roadmap for strengthening regulatory education. Regulatory Focus. Retrieved from http://www.raps.org/RegulatoryFocus/Features/2014/09/04/20213/Core-Competencies-Provide-Roadmap-for-StrengtheningRegulatory-Education/

Stewart, M., Reid, G., Brown, J. B., Burge, F., DiCenso, A., Watt, S., . . Meredith, L. (2010). Development and implementation of training for interdisciplinary research in primary health care. Academic Medicine, 85(6), 974-979. https://doi.org/10.1097/ACM.0b013e3181dbe31f

Tarrant, S. P., \& Thiele, L. P. (2017). Enhancing and promoting interdisciplinarity in higher education. Journal of Environmental Studies and Sciences, 7(2), 355-360. https://doi.org/10.1007/s13412-016-0402-9

Thompson, J. (1967). Organizations in action: Social science bases of administrative theory. New York: McGraw Hill. 
TOPRA. (2013). MSc in regulatory affairs. Retrieved from https://www.topra.org/TOPRA/TOPRA Member/mscra/MSc Regulatory Affairs.aspx

van der Laan, J. W., \& DeGeorge, J. J. (2013). Global approach in safety testing: ICH guidelines explained (1 ed. Vol. 5). New York: Springer-Verlag. https://doi.org/10.1007/978-1-4614-5950-7

Vozeh, S. (1995). The international conference on harmonisation. European Journal of Clinical Pharmacology, 48(3), 173-175. https://doi.org/10.1007/BF00198293

Weingart, P. (2000). Interdisciplinarity: The paradoxical discourse. In P. Weingart \& N. Stehr (Eds.), Practising interdiciplinarity (pp. 25-42). Toronto: University of Toronto Press.

\section{BIOGRAPHY}

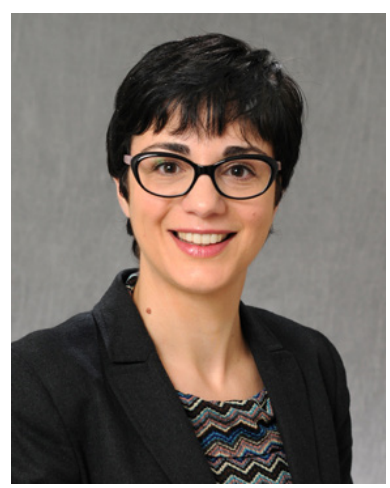

Daniela Drago, PhD, RAC is an assistant professor and the director of the Regulatory Affairs Programs at the George Washington University School of Medicine and Health Sciences, Washington, DC USA. Prior to joining academia, she held senior positions inn global regulatory and medical affairs in the pharmaceutical and medical device industries. Currently, she is the elected president of the Association of Graduate Regulatory Educators (AGRE) and serves on the boards of directors of the Regulatory Affairs Certification Board (RACB).

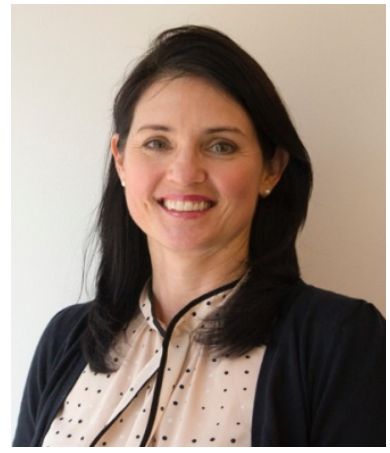

Paige L. McDonald, EdD, is an assistant professor at the George Washington University School of Medicine and Health Sciences, Washington, DC USA where she is the Director of Curriculum in the PhD inn Translational Health Sciences Program. She is the Managing Director for the GW IMPACT Initiative and GW Collaboratory for Health Research and Education. She is also the Secretary of the International Society for Systems and Complexity Science for Health.

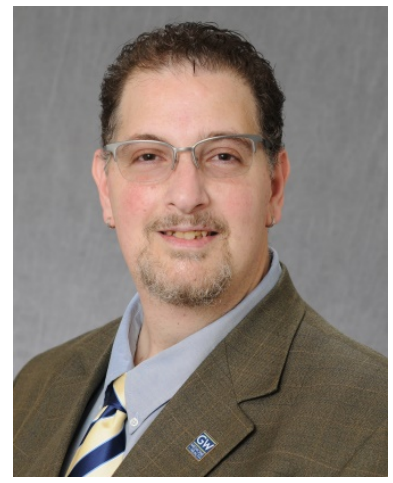

Gaetano R. Lotrecchiano, EdD, PhD in an associate professor at the George Washington University School of Medicine and Health Sciences, Washington, DC USA where he is the Director of Doctoral Candidacy in the PhD inn Translational Health Sciences Program. He is the foundational Vice-President for the International Society for Systems and Complexity Science for Health and the International Network for the Science of Team Science. He is the convener of the GW program entitled Creating a Culture of Collaboration at GWU. He also the Team Science Lead for the Clinical and Translational Science Institute (CTSI-CN), a partnership between Children's National Health System and George Washington University. 